\title{
Inflammasome Inhibition Suppresses Alveolar Cell Permeability Through Retention of Neuregulin-1 (NRG-1)
}

\author{
Rajanbabu Venugopal Lakshmi Galam Ruan Cox Jutaro Fukumoto Young Cho \\ Prasanna Tamarapu Parthasarathy Richard F. Lockey Narasaiah Kolliputi \\ Division of Allergy and Immunology, Department of Internal Medicine, Morsani College of Medicine, \\ University of South Florida, Tampa FL, USA
}

\section{Key Words}

Macrophage - Inflammasome - Alveolar cell permeability - Reactive oxygen species - Acute lung injury $\bullet$ IL-1 $\beta$

\begin{abstract}
Background: Neuregulin (NRG)-1-human epidermal receptor (HER)-2 signaling pathway is a key regulator of IL-1 $\beta$-mediated pulmonary inflammation and epithelial permeability. The inflammasome is a newly discovered molecular platform required for caspase- 1 activation and maturation of IL-1 $\beta$. However, the role of the inflammasome in NRG-1-HER2 signalingmediated alveolar cell permeability is unknown. Methods: The inflammasome was activated or inhibited in THP-1 cells; supernatants from these cells were added to A549 cells and human small airway epithelial cells (HSAEC). The protein expression of NRG-1 and phospho-HER2 (pHER2) were measured by Western blot analysis and epithelial permeability was measured using Lucifer yellow dye. Results: Results reveal that alveolar permeability in A549 cells and HSAEC is increased when treated with supernatants of inflammasome-activated THP1 cells. Alveolar permeability is significantly suppressed when treated with supernatant of inflammasome-inhibited THP-1 cells. Inflammasome-mediated permeability is decreased when A549 cells and HSAEC are pretreated with IL-1 $\beta$ receptor antagonist (IL-1 $\beta R A)$. In addition, HER2 kinase inhibitor AG825 or NRG-1 inhibitor TAPI inhibits inflammasomemediated permeability in A549 cells and HSAEC demonstrating critical roles of IL-1 $\beta$, NRG1 , and HER2 in inflammasome-mediated alveolar permeability. Conclusion: These findings suggest that inflammasome-induced alveolar cell permeability is mediated by NRG-1/HER2 signaling through IL-1 $\beta$ regulation.
\end{abstract}

Narasaiah Kolliputi,

KARGER 125
Division Allergy and Immunology, Department of Internal Medicine, College of Medicine, University of South Florida, 12901 Bruce B. Downs Blvd, Tampa, FL 33612 (USA)

Tel. +1813-974-5419, Fax +1813-974-8575, E_Mail nkollipu@health.usf.edu 


\section{Cellular Physiology Cell Physiol Biochem 2015;36:2012-2024 \begin{tabular}{l|l} 
and Biochemistyy Published onlIne: July 17, 2015 & $\begin{array}{l}\text { C 2015 S. Karger AG, Basel } \\
\text { www.karger.com/cpb }\end{array}$ \\
\hline Wenugopal et al: Inflammasome Regulates Alveolar Cell Permeability through NRG-1
\end{tabular}}

\section{Introduction}

Acute lung injury (ALI) is a major clinical disorder in the United States which affects approximately 200,000 patients annually with $40 \%$ mortality [1]. ALI causes ventilation perfusion mismatch, severe hypoxemia, and poor lung compliance [2]. Intact epithelial and endothelial cells are necessary to maintain alveolar barrier function in lungs [3]. Disruption of this epithelial integrity causes increased permeability and alveolar flooding with proteinrich edema fluid which is a hallmark of ALI/ARDS [4]. The alveolar capillary membrane cells and innate immune system cells are targets of damage and effectors of injury in ALI [4].

The proinflammatory cytokine interleukin (IL)-1 $\beta$ is the most significant cytokine in the lungs of ALI patients and is produced by differentiated macrophages and epithelial cells [5]. It leads to the subsequent production of chemokines and inflammatory cytokines such as TNF- $\alpha$ or IL-6 [5]. IL-1 $\beta$ regulates numerous downstream candidates in ALI [5-8]; moreover, IL-1 $\beta$ is involved in the regulation of cell permeability and migration $[3,9]$.

The inflammasome is a multiprotein complex that mediates the processing and production of mature IL-1 $\beta$ in differentiated monocytes and macrophages $[10,11]$. Two signals are required for inflammasome activation $[12,13]$. First, the NF- $\kappa B$ signal activates the NOD- like receptors (NLR) protein, an inflammasome component and IL-1 $\beta$ precursor $[14,15]$. The second signal stimulates the inflammasome complex assembly which activates caspase-1 [16-18] and, in turn, activates IL-1 $\beta[12,19]$. The inflammasome is activated by ATP through $\mathrm{P} 2 \mathrm{X}_{7}$ receptors [20] in response to low intracellular potassium levels; increased extracellular potassium and the pharmacological compound glyburide block its activity.

Previously, we demonstrated the involvement of the inflammasome in hyperoxiainduced ALI [21]. The signaling protein neuregulin-1 (NRG-1) is a molecule which mediates cell-to-cell interaction and plays a critical role in growth; it is essential for the development of the nervous and cardiovascular system [22-25]. NRG-1 is normally intact with the cell; in addition, a disintegrin and metalloprotease 17 (ADAM-17) mediates NRG-1 shedding [26]. Reports show that IL-1 $\beta$ increases epithelial cell permeability by releasing intact NRG- 1 into the extracellular space [27]. Released NRG-1 acts on the Human Epidermal growth factor Receptor (HER) family of receptors, and in response, HER3 is heterodimerized with HER2 [28]. Heterodimerization results in the activation of the HER2 tyrosine kinase domain which increases alveolar permeability [27]. Since IL-1 $\beta$ modulates ADAM-17 and NRG-1 interaction leading to induction of NRG-1-mediated HER2 signaling [26] and epithelial permeability, regulating IL-1 $\beta$ secretion presents a logical approach to prevent the loss of NRG-1-mediated cell integrity.

Present ALI therapies focus on neutralizing excess IL-1 $\beta$ or proinflammatory cytokines $[29,30]$. However, the IL-1 $\beta$ receptor antagonist (IL-1 $\beta R A$ ) based therapy did not show any beneficial effects [31]. Considering the role of the inflammasome in IL-1 $\beta$ processing and secretion, directly targeting the inflammasome to inhibit the generation of IL-1 $\beta$ presents a better clinical approach to ameliorate the cytokine storm in ALI. However, the role of the inflammasome in relation to NRG-1-mediated HER2 signaling leading to epithelial permeability remains unknown.

In this study, we examine the effect of the inflammasome on NRG-1-mediated epithelial permeability. Results show that inflammasome activation leads to increased epithelial permeability. Furthermore, inflammasome activation induces NRG-1 shedding. Results also indicate that NRG-1-mediated HER2 activation occurs though inflammasome activation and that NRG-1 shedding is inflammasome dependent. The findings in this report reveal a signaling pathway that may have novel therapeutic value to suppress alveolar cell permeability for patients with ALI.

\section{Materials and Methods}

Cell culture

A549 cells from human lung adenocarcinoma were obtained from American Type Culture Collection (ATCC, Manassas, VA) and were maintained in DMEM medium according to the vendor's instructions. 


\section{Cellular Physiology Cell Physiol Biochem 2015;36:2012-2024 \begin{tabular}{ll|l} 
and Biochemistry & $\begin{array}{l}\text { DOI: 10.1159/000430169 } \\
\text { Published onIIne: July 17, } 2015\end{array}$ & $\begin{array}{l}\text { C) 2015 S. Karger AG, Basel } \\
\text { www.karger.com/cpb }\end{array}$ \\
\hline
\end{tabular}}

Human small airway epithelial cells (HSAEC, ATCC) were purchased from Lonza and cultured as mentioned in the supplier recommendations.

\section{Reagents and antibodies}

PMA (Sigma-Aldrich, St. Louis, MO, USA), nigericin (Sigma-Aldrich), glyburide (Sigma- Aldrich), ATP (Enzo lifesciences, Farmingdale, NY, USA), KCl (Sigma-Aldrich), TAPI-2 (EMD chemicals, Gibbstown, NJ, USA), AG-825 (EMD chemicals), recombinant human IL-1 $\beta$ (rhIL-1 $\beta$, R\&D systems, Minneapolis, MN, USA) and IL-1 $\beta$ RA (rhIL-1 $\beta$, R\&D systems) were purchased from its respective vendors. The following secondary antibodies were used to detect protein expression: Anti-rabbit HER2 (Santacruz biotechnology, Santa Cruz, CA, USA), anti-rabbit pHER2 (Santacruz biotechnology), anti-mouse NRG-1(Neo markers, Fremont, CA, USA) primary, anti-mouse (Cell Signaling Technology, Danvers, MA, USA) and anti-rabbit (Cell Signaling Technology).

\section{Treatment with inflammasome stimulators or inhibitors}

THP- 1 cells were differentiated by adding $0.5 \mu \mathrm{g} / \mathrm{ml}$ of PMA to the medium for 3 hours, then the medium was replaced with RPMI plus $0.1 \%$ serum overnight. After 24 hours, cells were briefly washed with PBS. Then, $0.5 \mu \mathrm{g} / \mathrm{ml}$ of nigericin or $0.25 \mathrm{mM}$ ATP, in the presence or absence of $1.25 \mu \mathrm{g} / \mathrm{ml}$ glyburide or $130 \mathrm{mM} \mathrm{KCl}$, was added to the medium for 1 hour. The activation of the inflammasome was confirmed by measuring the IL- $1 \beta$ secretion, and the supernatant was added to $80 \%$ confluent epithelial or endothelial cells for up to $5 \%$ of the mentioned time.

\section{Cell Permeability Measurement}

The permeability was assessed in HSAEC and A549 monolayers on a BD Falcon 96-multiwell insert platform (BD Biosciences, Bedford, MD, USA) using measured passage of Lucifer yellow dye (Sigma-Aldrich). Monolayers in the hanging insert were incubated with the required concentration of THP-1-conditioned supernatants or IL-1 $\beta$ with or without mentioned inhibitors for 24 hours. PMA-conditioned medium in the absence of other additives was used as control cells. To analyze permeability, Lucifer yellow dye $(100 \mu \mathrm{g} /$ $\mathrm{ml}$ ) in HBSS was added to the monolayer in the top well, and the bottom well was filled with $270 \mu \mathrm{l}$ HBSS. After 1-4 hours, fluorescence in the bottom well was measured by spectrophotometer at excitation $485 \mathrm{~nm}$ and emission $510 \mathrm{~nm}[21,27]$. The permeability coefficient was calculated as directed by the 96 -multiwell insert platform supplier (BD Biosciences).

\section{Western blot}

Cells were lysed with RIPA buffer and protein concentration was determined by using the BCA assay kit. Uniform quantity of protein, as assessed by BCA assay, was run on SDS-PAGE, and protein was transferred to the PVDF membrane by following the previously mentioned method [32]. The membrane was blocked for 1 hour in PBS/T (PBS containing 0.05\% TWEEN 20) containing 5\% nonfat dry milk. Primary and secondary antibodies were diluted to 1000 -fold in PBS/T with $2.5 \%$ nonfat milk. Probing with antibodies and washing steps were followed as previously mentioned [32]. Protein levels were detected using a Pierce ECL Western blotting substrate kit (Thermo scientific Rockford, IL, USA) according to the manufacturer's instructions and exposed in a ChemiDoc XRS (Biorad, Hercules, CA, USA). The intensity of bands were measured and normalized to GAPDH.

\section{Measurement of IL-1 $\beta$ and NRG-1 secretion}

Human IL-1 $\beta$ ELISA Ready-SET-Go kit (eBioscience, San Diego, CA, USA) was used to quantify the IL-1 $\beta$ levels in the THP-1 cell culture supernatant according to the manufacturer instructions [21]. The secretion of NRG-1 was measured by using Duoset human NRG1- $\beta 1$ kit according to the manufacturer instructions with minor modifications (R\&D technologies, Minneapolis, MN, USA) [33].

\section{Statistics}

Data was statistically analyzed by GraphPad Prism version 10.00 for Windows (GraphPad Software, San Diego, CA). Comparison of continuous variables between two groups was performed using Student's $t$-test. All tests were two-tailed and results were considered significant at $\mathrm{p}<0.05$. 


\section{Cellular Physiology Cell Physiol Biochem 2015;36:2012-2024

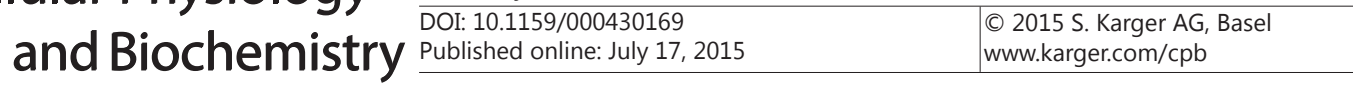 \\ Venugopal et al.: Inflammasome Regulates Alveolar Cell Permeability through NRG-1}

\section{Results}

Inflammasome activators increases IL-1 $\beta$ secretion in THP-1 supernatants

In the initial experiments, we sought to determine if inflammasome activators can induce IL-1 $\beta$ processing and secretion in THP-1 cells. For this current study, THP-1 cells were selected because of their similarity to the activated alveolar macrophages present in bronchoalveolar lavage (BAL) fluid [21]. In addition, differentiated THP-1 cells have a unique characteristic feature of processing and secretion of IL-1 $\beta$ mediated by inflammasome activation. THP-1 cells were initially differentiated using $0.5 \mu \mathrm{g} / \mathrm{ml}$ of PMA. Differentiated THP-1 cells were treated with either $0.5 \mu \mathrm{g} / \mathrm{ml}$ of nigericin or $0.25 \mathrm{mM}$ ATP to induce inflammasome activation. The levels of mature IL-1 $\beta$ (end product of the inflammasome) in THP-1 supernatants by ELISA were measured. Results revealed that inflammasome activators nigericin and ATP increase the levels of IL-1 $\beta$ in supernatants but, inflammasome inhibitor glyburide suppresses nigericin- or ATP-induced (inflammasome-mediated) IL-1 $\beta$ processing and secretion (Fig. 1A). Western blot analysis probed for mature IL-1 $\beta$ from the inflammasome activators nigericin and ATP treatments showed similar results consistent with ELISA (Fig. 1B). These results indicate that nigericin and ATP induce inflammasome complex formation thereby increasing the inflammasome-mediated IL- $1 \beta$ secretion in THP1 culture supernatants. Supernatants from these THP-1 cells (inflammasome induced and/ or suppressed) were referred as conditioned supernatants, and were used to assess the functional effects of the inflammasome in further experiments.

\section{Activation of the inflammasome increases alveolar epithelial permeability in HSAEC}

Activated alveolar macrophages release inflammatory cytokines which leads to an increase in epithelial permeability and cell injury that ultimately causes cell death in ALI. However, the functional effects of inflammasome activation on epithelial permeability are not clearly defined. To determine this, THP-1 cells were treated with inflammasome activators and/or inhibitors; then the conditioned supernatants were added to primary HSAEC. After 24 hours, permeability was measured by calculating the penetration of Lucifer yellow dye. Our data showed an increase in epithelial permeability in HSAEC when treated with inflammasome-activated supernatants from THP-1 cells. However, supernatants from THP1 cells treated with inflammasome inhibitors like glyburide or $\mathrm{KCl}$ decrease the permeability (Fig. 2A-2D). To avoid the possible additional cytotoxic effects of nigericin, ATP, glyburide, or

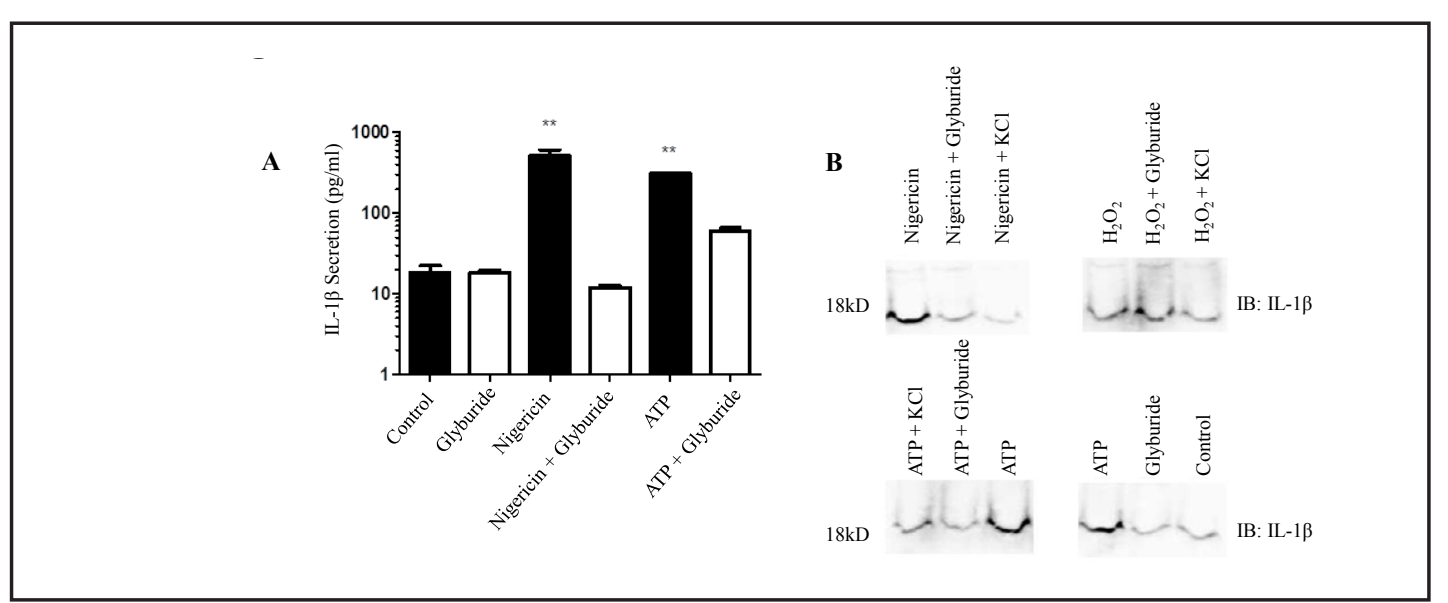

Fig. 1. Inflammasome activators increased IL-1 $\beta$ secretion in THP-1 supernatants. THP-1 cells were activated with $0.5 \mu \mathrm{g} / \mathrm{ml}$ of PMA, and the cells were treated with $0.5 \mu \mathrm{g} / \mathrm{ml}$ of nigericin, $0.25 \mathrm{mM}$ ATP, or $0.25 \mathrm{mM}$ of $\mathrm{H}_{2} \mathrm{O}_{2}$ in the presence or absence of $1.25 \mu \mathrm{g} / \mathrm{ml}$ of glyburide or $130 \mathrm{mM} \mathrm{KCl}$ for 1 hour. [A] Mature IL-1 $\beta$ levels in the supernatant were measured by ELISA $(\mathrm{r}=3 ; \mathrm{n}=2) .{ }^{*} \mathrm{P}<0.01$ when compared between the control and nigericin and between the control and ATP. [B] Immunoblot shows mature IL-1 $\beta$ in the supernatant. The noted experiments are representative of a minimum of three similar evaluations. 


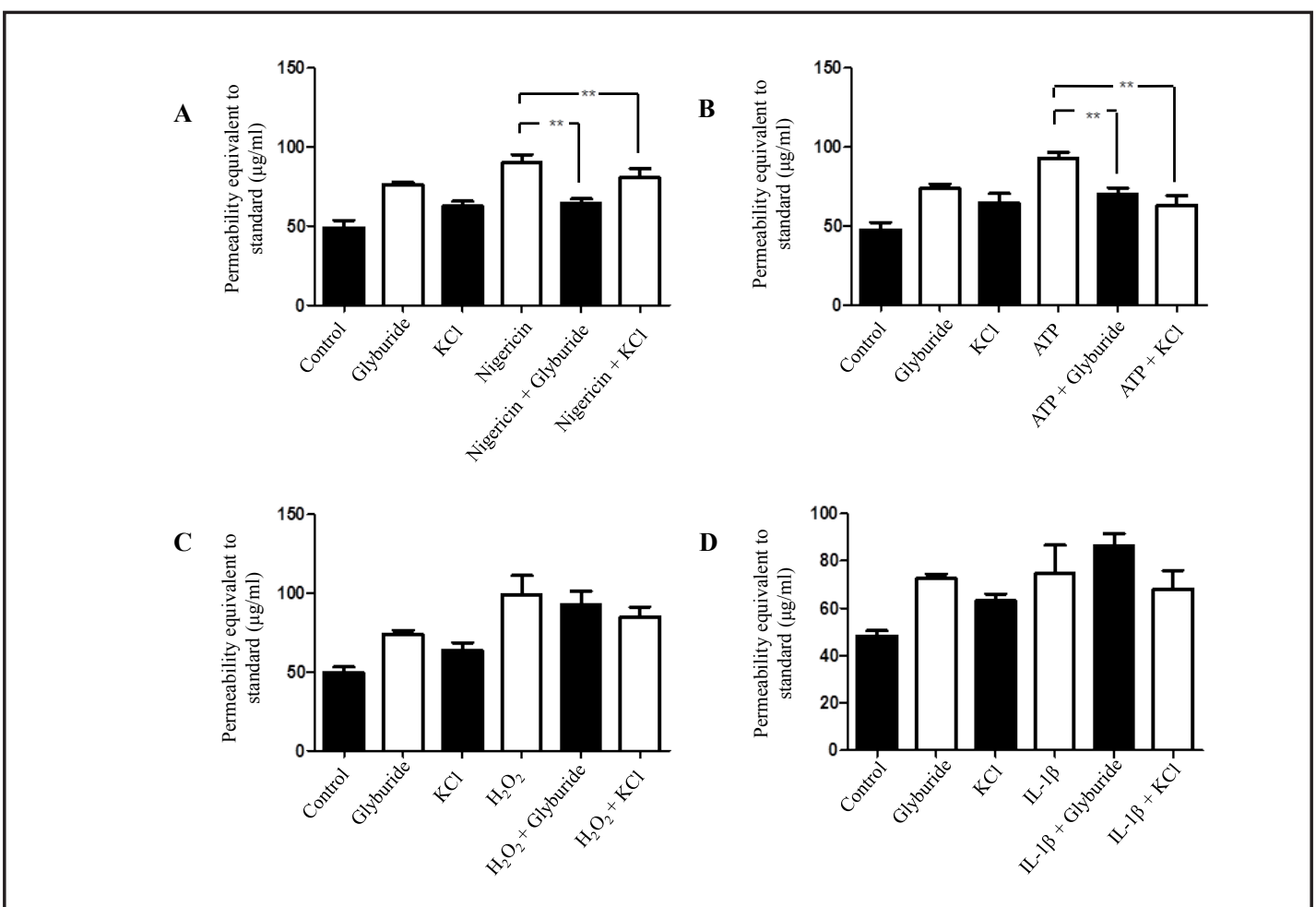

Fig. 2. Activation of the inflammasome increased permeability in HSAEC. THP-1 cells were treated with nigericin, ATP, and $\mathrm{H}_{2} \mathrm{O}_{2}$ in the presence or absence of glyburide or $\mathrm{KCl}$, and the conditioned supernatants were added to HSAEC monolayer cells grown in 96 upper insert wells for 24 hours. [A-D] Permeability was measured by calculating the transfer of Lucifer yellow dye from upper insert containing monolayered cells to the bottom of the well. Permeability was displayed relative to concentration of Lucifer yellow dye in the empty wells. $(\mathrm{r}=2 \sim 3 ; \mathrm{n}=3){ }^{* *} \mathrm{P}<0.01$ when compared between nigericin and nigericin+glyburide, nigericin and nigericin $+\mathrm{KCl}$, ATP and ATP+glyburide, ATP and ATP $+\mathrm{KCl}$. The noted experiments are representative of a minimum of three similar evaluations.

$\mathrm{H}_{2} \mathrm{O}_{2}$ in THP- 1 supernatants, HSAEC were treated with concentrations ranging from 0.125 to $1 \mu \mathrm{g} / \mathrm{ml}$ of nigericin, 0.3125 to $2.5 \mu \mathrm{g} / \mathrm{ml}$ of glyburide, and 0.0625 to $0.5 \mathrm{mM}$ of ATP or $\mathrm{H}_{2} \mathrm{O}_{2}$, and cytotoxicity was determined by MTT assay (Fig. 3A-3D). The concentrations of $0.5 \mu \mathrm{g} / \mathrm{ml}$ of nigericin, $1.25 \mu \mathrm{g} / \mathrm{ml}$ of glyburide, $0.25 \mathrm{mM}$ of ATP, or $\mathrm{H}_{2} \mathrm{O}_{2}$ transferred along with the $5 \%$ of THP- 1 culture supernatants did not affect the cell viability in HSAEC. These results suggest that inflammasome activation induces alveolar macrophage-mediated production of IL-1 $\beta$ which causes a significant increase in alveolar epithelial permeability.

\section{Inflammasome inhibitors increases the retention of NRG-1 in HSAEC}

Studies suggest that NRG-1 shedding induces alveolar epithelial permeability leading to epithelial barrier dysfunction thereby causing ALI. Based on the observations that inflammasome activation increases alveolar epithelial permeability, it was hypothesized that inflammasome activation and increased alveolar permeability is mediated through shedding of NRG-1. To investigate this mechanism, supernatants from inflammasome-induced and/ or suppressed THP-1 cells were added to HSAEC. In another set of experiments, THP-1 cells were exposed to recombinant human IL-1 $\beta$ or nigericin in the presence or absence of glyburide or IL-1 $\beta$ RA; the supernatants were added to HSAEC. NRG-1 retention content from whole cell lysates from all of the experiments mentioned above was analyzed by Western blot. The addition of nigericin- or ATP-treated conditioned medium to HSAEC decreased the retention levels of NRG-1 when compared to untreated supernatants as indicated by the intracellular protein content. Also, inflammasome inhibition by glyburide increased the 
A

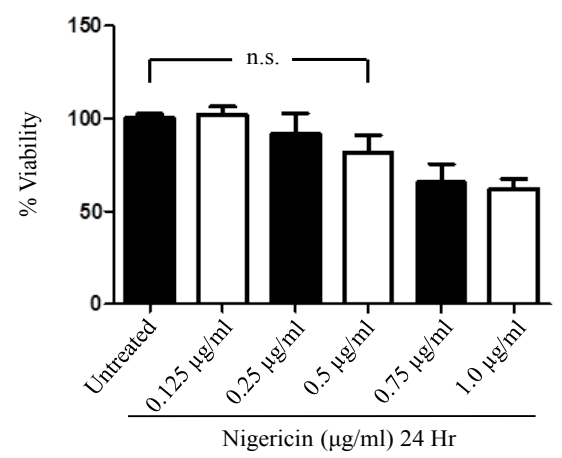

C

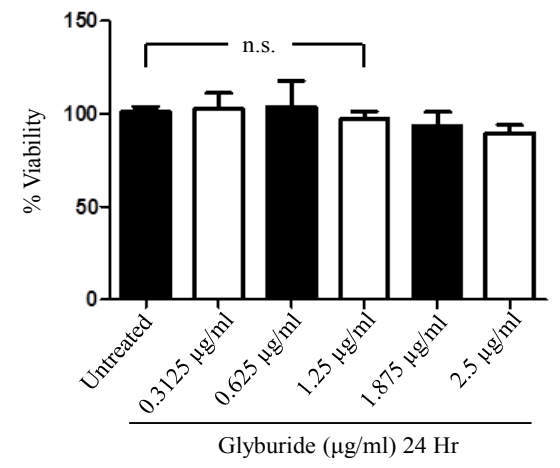

B

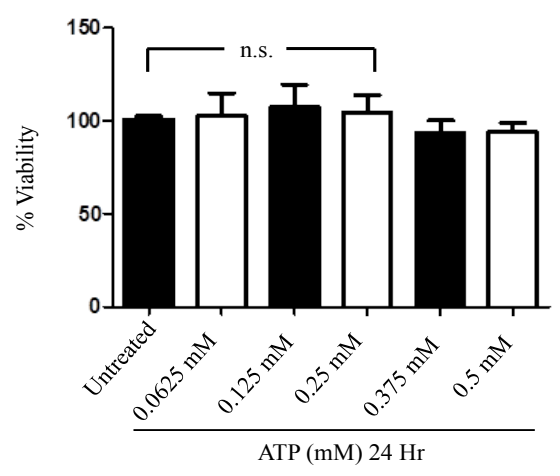

D

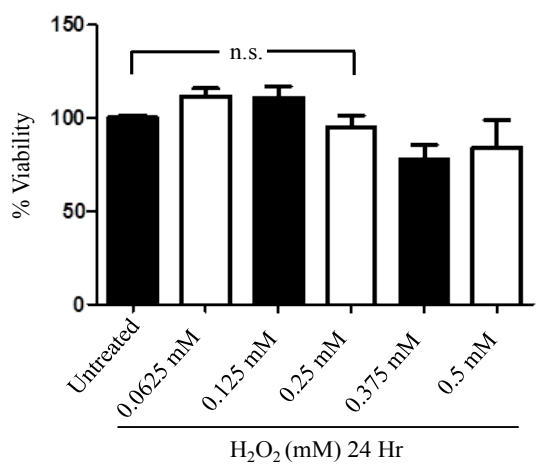

Fig. 3. Experimental dose of glyburide, nigericin, ATP, and $\mathrm{H}_{2} \mathrm{O}_{2}$ does not affect the cell viability. Overnight cultured A549 cells were treated with various doses of [A] nigericin, [B] ATP, [C] glyburide, or [D] $\mathrm{H}_{2} \mathrm{O}_{2}$ After 24 hours, cell viability was measured by MTT assay and displayed as relative percent to untreated control (\% viability). The noted experiments are representative of a minimum of three similar evaluations.

A
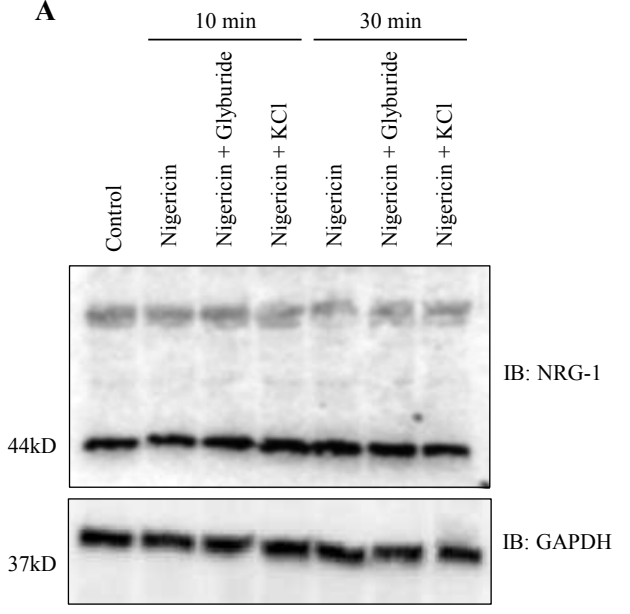

B
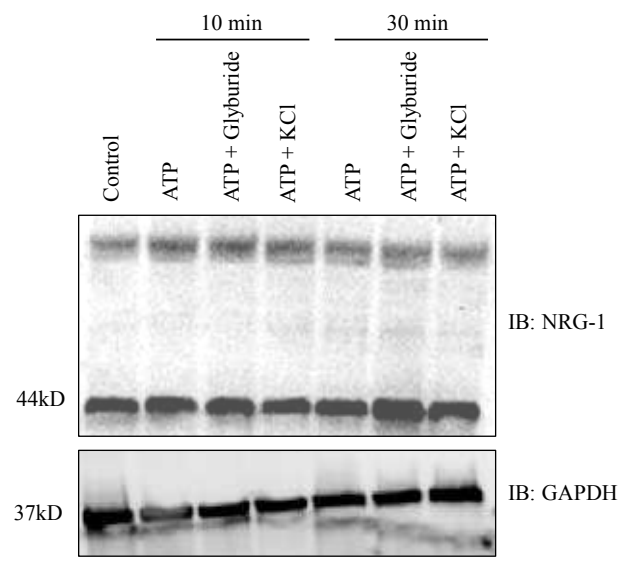

Fig. 4. The inflammasome reduces intact NRG-1 level in HSAEC. THP-1 cells were exposed to [A] nigericin or [B] ATP in the presence or absence of glyburide or KCl. HSAEC were later treated with various conditioned media from THP- 1 cells for 10 or 30 minutes. NRG-1 levels in response to treatments with nigericin and ATP combinations in $50 \mu \mathrm{g}$ of total cell lysates (HSAEC) was displayed in immunoblot (top), and the corresponding intensity ratio between NRG-1 and GAPDH are shown (bottom). The noted experiments are representative of a minimum of three similar evaluations.

retention of NRG-1 in whole cell HSAEC lysates (Fig. 4A-4B). Since IL-1 $\beta$ is the end product of the inflammasome, we tested whether IL-1 $\beta$ can modulate NRG-1 shedding by exposing HSAEC to recombinant human IL-1 $\beta$. Results indicate that IL-1 $\beta$ induced NRG-1 shedding 


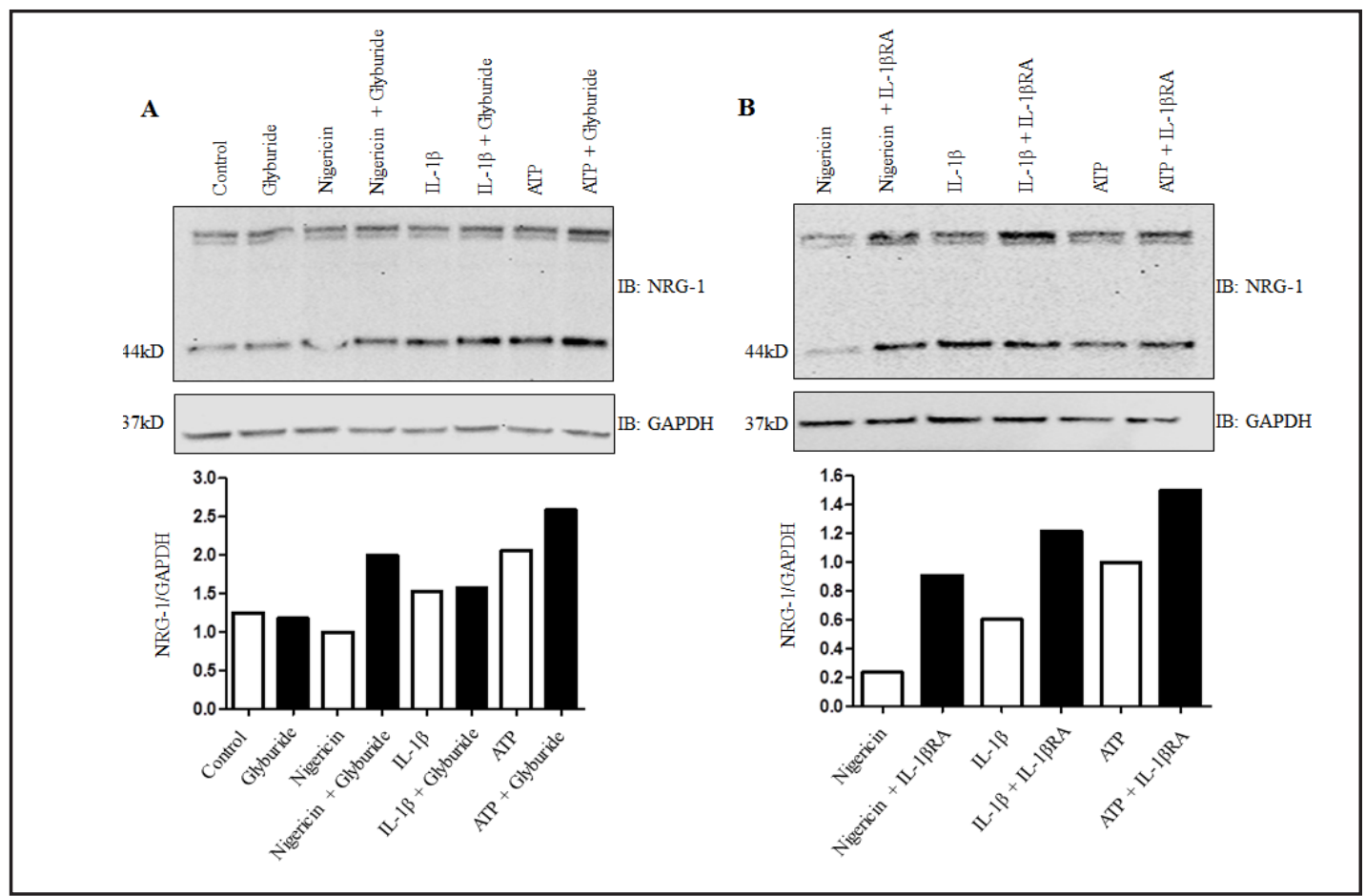

Fig. 5. Glyburide increases retention of NRG-1 in HSAEC. [A] THP-1 cells were treated with nigericin and ATP in the presence or absence of glyburide and the conditioned supernatants were added to HSAEC for 1 hour. In addition, IL-1 $\beta$ (10 ng/ml) was directly added to HSAEC to study the effect of IL-1 $\beta$. NRG-1 in 50 $\mu \mathrm{g}$ of total cell lysates was studied by immunoblot (top) and intensity ratio of NRG1/GAPDH was obtained (bottom). [B] To inhibit the IL-1 $\beta$ signaling, IL-1ßRA was added 1 hour prior to the addition of conditioned media and NRG-1 expression was studied by immunoblot (top) and intensity ratio of NRG1/GAPDH (bottom). The noted experiments are representative of a minimum of three similar evaluations.

(Fig. 5A-5B). The pretreatment of IL-1 $\beta R A$ prevented the nigericin-, IL-1 $\beta-$, or ATP-mediated decrease in NRG-1 in whole cell lysates (Fig. 5B). These results suggest that inflammasome suppression increases the retention of NRG-1 in HSAEC.

\section{Inflammasome activation increases the $N R G$-1 release}

NRG-1 shedding and HER2 activation participate in epithelial barrier dysfunction in ALI, additionally, elevated NRG-1 levels have been detected in blood samples from patients with ALI [27]. NRG-1 content was analyzed by ELISA to confirm whether reduced retention of NRG-1 by the inflammasome is due to the shedding and secretion of NRG-1 into supernatant. Subsequently, THP-1 cells were activated and/or inhibited using ATP or nigericin in the presence or absence of glyburide or $\mathrm{KCl}$, and the supernatants from these treatments were added to HSAEC and A549 cells. The amount of NRG-1 in the supernatants was measured by ELISA. In HSAEC and A549 cells, supernatants collected from THP-1 treatments with nigericin or IL-1 $\beta$ increased NRG-1 secretion, whereas glyburide and IL-1 $\beta$ RA prevented this effect (Fig. 6A-6B). These results confirm that inflammasome activation increases the shedding of NRG-1 and lowered the retention levels of NRG-1 in HSAEC and A549 cells.

\section{The inflammasome activates HER2}

NRG-1 is a known ligand for HER2 signaling [28]. The shedding of NRG-1, subsequent HER2 activation, and initiation of downstream signaling result in the loss of alveolar and airway epithelial barrier function and pulmonary edema [27, 34]. These findings indicate that inflammasome activation induces NRG-1 shedding, confirming the downstream effects of the inflammasome on NRG-1 shedding-mediated activation of HER2. The expression of 
A

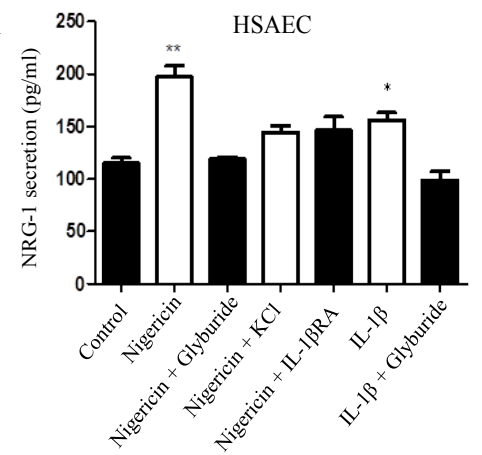

B

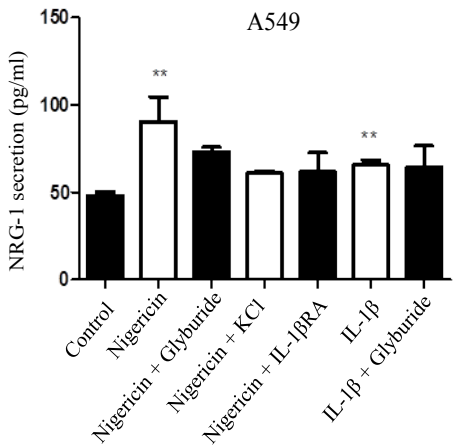

Fig. 6. Inflammasome activation increases the shedding of NRG-1 in A549 cells and HSAEC. THP-1 cells were activated and/or inhibited using ATP or nigericin in the presence or absence of glyburide or $\mathrm{KCl}$, and the conditioned supernatant were added to HSAEC and A549 cells. IL-1 $\beta$ RA was added 1 hour prior to IL-1 $\beta$ addition to suppress the IL-1 $\beta$ influence on these cells. The secretions of NRG-1 in supernatants obtained from $[\mathrm{A}]$ HSAEC and [B] A549 cells were measured by ELISA. $* * \mathrm{P}<0.01$ when compared between control and nigericin in HSAEC and A549 cells and between control and IL-1 $\beta$ in A549 cells (Student t-test). The noted experiments are representative of a minimum of three similar evaluations.

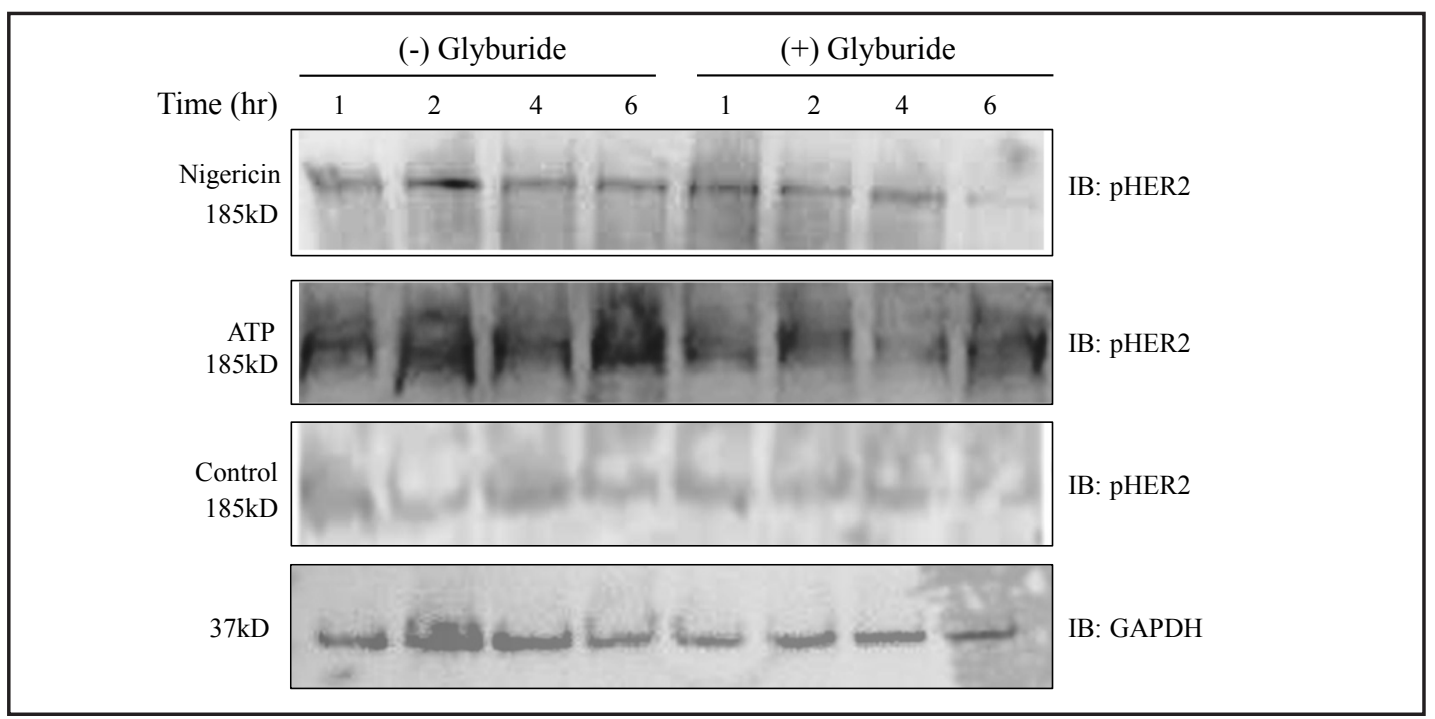

Fig. 7. The inflammasome activates HER2. A549 cells were incubated with nigericin, ATP, or as a control in the presence or absence of glyburide-treated THP-1 supernatants for 1, 2, 4, and 6 hours. Expression of pHER2 and GAPDH in $50 \mu \mathrm{g}$ protein was compared. The noted experiments are representative of a minimum of three similar evaluations.

pHER2 in whole cell lysates was detected by Western blot analysis. Supernatants from THP1 cells treated with nigericin or ATP in the presence or absence of glyburide were added to A549 cells. At 1, 2, 4, and 6 hour post-addition, the expression of pHER2 in whole cell lysates of A549 was checked by Western blot analysis. Inflammasome activators (nigericin and ATP) increased the expression of pHER2, whereas the presence of glyburide decreased the expression levels (Fig. 7). This shows that activation of the inflammasome increases the shedding of NRG-1 into the supernatants and results in the activation of HER2.

\section{Activation of HER2 by the inflammasome is IL-1 $\beta$ dependent}

Supernatants from THP- 1 cells treated with nigericin or ATP in the presence or absence of glyburide were added to A549 cells to investigate the involvement of IL-1 $\beta$ in inflammasome- 


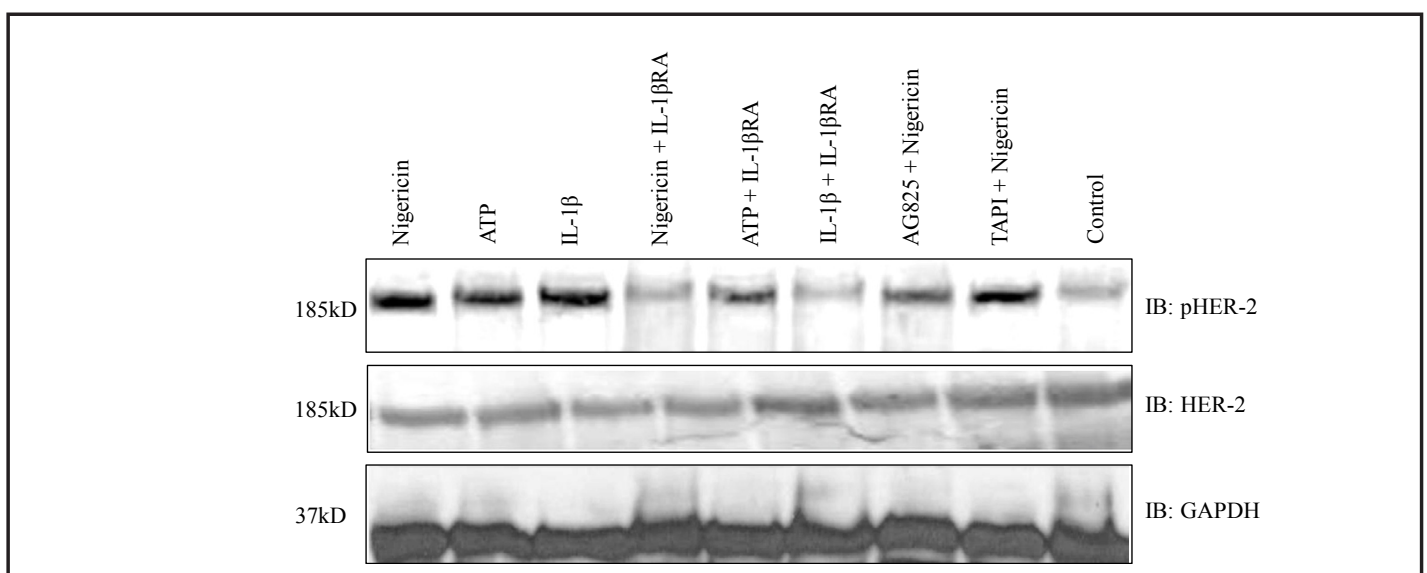

Fig. 8. Activation of pHER2 is IL-1 $\beta$ dependent. HSAEC were treated with conditioned media from THP-1 cells exposed with nigericin and ATP for 1 hour. Recombinant IL-1 $\beta$ (I) was directly added to HSAEC. IL1ßRA, TAPI, or AG825 molecules were added 1 hour prior to the addition of the conditioned supernatants to block the NRG-1 and HER2 signaling. The expression of pHER2, HER2, and GAPDH in $50 \mu \mathrm{g}$ of total cell lysates was checked by immunoblot analysis. The noted experiments are representative of a minimum of three similar evaluations.

Fig. 9. Inflammasome-mediated increase in cell permeability is IL-1 $\beta$ dependent. A549 cells were pretreated with THP-1-conditioned supernatants exposed to nigericin, ATP, glyburide, and $\mathrm{KCl}$ for 24 hours. IL-1ßRA was added 1 hour before treatment. The relative permeability assessed by using a Lucifer yellow dye based assay. HSAEC treated with glyburide or KCl exposed THP-1-conditioned supernatants along with IL-1 $\beta$ and permeability was calculated. ${ }^{* *} \mathrm{P}<0.01$ when compared between control and nigericin, control and ATP, nigericin with and without

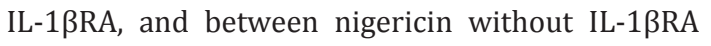
and ATP with IL-1 $\beta$ RA (Student t-test). The noted experiments are representative of a minimum of three similar evaluations.

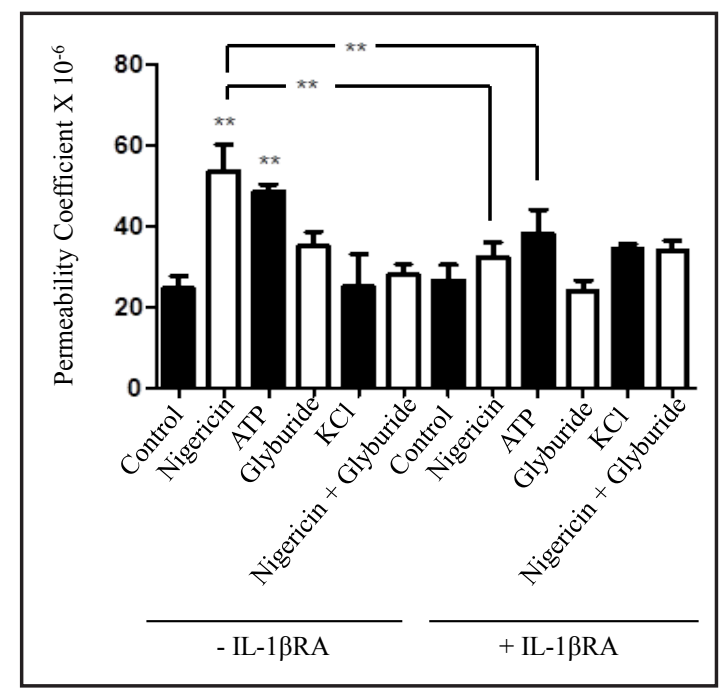

mediated activation of HER2. The A549 cells were treated with inflammasome-activated supernatants or human recombinant IL-1 $\beta$ in the presence or absence of IL-1 $\beta R A$. Our results showed that the presence of IL-1 $\beta$ RA prevented the induction of pHER2 demonstrating that the inflammasome-mediated regulation is IL-1 $\beta$ dependent (Fig. 8). In addition, the effect of pHER2 activation inhibitor molecule and NRG-1 shedding blockade molecule on nigericinmediated activation of HER2 was investigated. Results suggest that TAPI-2 and AG-825 prevent nigericin-mediated activation of HER2.

The inflammasome effect on cell permeability is IL-1 $\beta$ dependent

Based on the observations above, it was hypothesized that inflammasome-mediated cell permeability is IL-1 $\beta$ dependent. IL-1 $\beta(10 \mathrm{ng} / \mathrm{ml})$ was directly added to HSAEC and cell permeability was analyzed to investigate whether inflammasome-mediated permeability occurs through IL-1 $\beta$. Results indicate that the addition of glyburide or $\mathrm{KCl}$ did not prevent the effect of IL-1 $\beta$-induced permeability (Fig. 9). A549 cells were also pretreated with or without IL-1 $\beta$ RA one hour prior to the addition of THP- 1 supernatant treated with activators and/or inhibitors of the inflammasome. Our results showed that nigericin- or ATP-treated 
supernatants increased the permeability, and the co-treatment of glyburide decreased the nigericin effect (Fig. 9). A decrease in nigericin- or ATP-mediated induction of permeability was observed in the IL-1 $\beta$ RA pretreated condition (Fig. 9). These results suggest that inflammasome-mediated cell permeability is IL-1 $\beta$ dependent.

\section{Discussion}

The majority of investigations on the inflammasome have been largely restricted to immune cells, so studying the influence of innate immune cells such as activated monocytes in alveolar epithelial dysfunction may provide a source for rapid integration of basic and clinical data for translational research [35]. Recent studies suggest novel contributors that may regulate activation of the inflammasome [36,37]. In addition, studies also demonstrate that underlying pathophysiologic factors in ALI such as alveolar epithelial barrier permeability and increased IL-1 $\beta$ levels are diminished [37]. The presented data links the functional effects of inflammasome activation on resident epithelial cells. The novel role of the inflammasome is discovered in NRG-1 shedding which results in downstream HER2 signaling and leads to an increase in alveolar epithelial permeability. NRG-1 levels are elevated in pulmonary edema fluid from patients with ALI receiving mechanical ventilation. Since this pathway induces NRG-1 retention, it may prove to be a worthy therapeutic approach to ALI. Blocking NRG-1 shedding will ultimately inhibit epithelial barrier dysfunction, the key event in ALI (Fig. 10). In our previous work, we observed that activation of the inflammasome leads to increased alveolar permeability in ALI [21]. The questions of whether inflammasome activation induces NRG-1 shedding, HER2 activation, and alveolar permeability elevation, a hallmark of ALI, are unknown. In this study, the inflammasome regulates paracrine activation of epithelial cell permeability. The implications of the proinflammatory cytokine IL- $1 \beta$ in lung injury is known in both in vitro and in vivo models [38-42]. Involvement of mature IL-1 $\beta$ in the disruption of epithelial cell permeability and modulation of NRG-1 and HER2 signaling has important implications in ALI and other pulmonary diseases [27]. However, the upstream mechanisms that initiate IL-1 $\beta$-mediated NRG-1 shedding and signaling of HER2 remain unknown.

In this report, the inflammasome was stimulated in THP-1 monocytes and supernatants from these cells were used to treat HSAEC and A549 cells. Low amounts of inflammasome

Fig. 10. Proposed mechanism of inflammasome-mediated activation of permeability. [1] ATP and nigericin stimulates the inflammasome complex formation. [2] NLRP3, ASC and active caspase-1 complex of the inflammasome cleaves the zymogen IL- $1 \beta$ into active form [3] Secreted IL-1 $\beta$ is released into circulation and acts upon epithelial or endothelial linings of airway. [4] IL-1 $\beta$ influences the ADAM-17 sheddase, and NRG-1 from the cell is shedded and released to extracellular space. [5] The released NRG-1 induces phosphorylation and activation of HER2 and further downstream signaling leads to loss of epithelial/endothelial lining integrity and increased alveolar permeability.

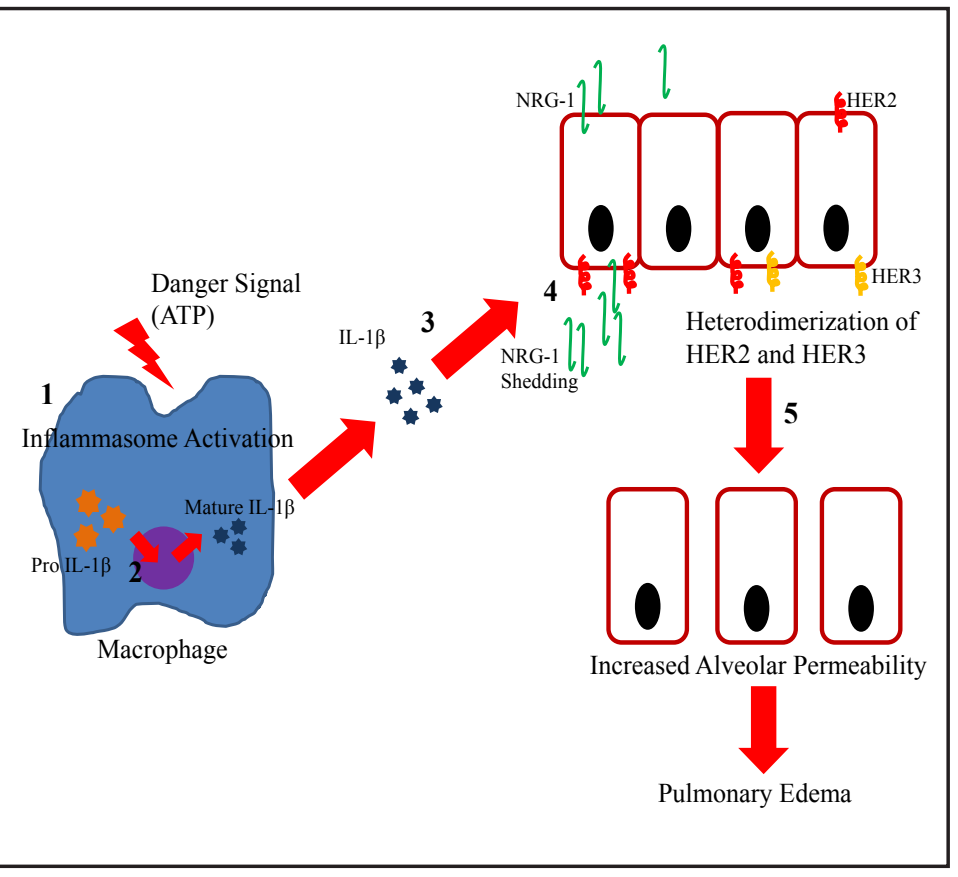




\section{Cellular Physiology Cell Physiol Biochem 2015;36:2012-2024

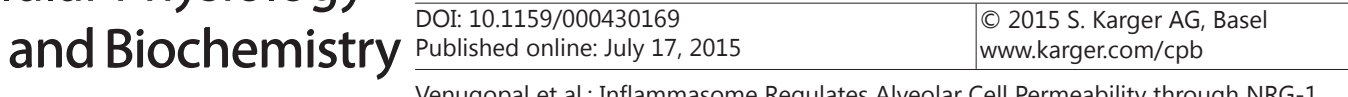

stimulating agents in the conditioned media could not activate the inflammasome in epithelial cells since the process is specific to immune cells like macrophages. Inflammasome activator-treated THP-1 supernatants increase the alveolar permeability whereas the presence of inflammasome inhibitors decreases the permeability in alveolar epithelial cells. The shedding of neuregulin is evidenced by decreased retention of NRG-1 in cell lysates and increased NRG-1 in supernatants of epithelial and endothelial cells when treated with supernatants from inflammasome-stimulated THP-1 cells. Similar to this model, ex vivo bone marrow macrophage supernatant-conditioned medium was used to study the inflammasome-mediated, insulin-induced Akt phosphorylation in a previous report [43]. Investigations also demonstrate that NRG-1 is released into extracellular space by ADAM17 sheddase molecule, and IL- $1 \beta$ downstream signaling further enhances the sheddase function of ADAM-17. Specific pharmacological inhibitor of ADAM-17 decreases HER2 activation in IL-1 $\beta$-stimulated epithelial cells consistent with previous studies with TAPI-2 in IL-1 $\beta$-stimulated epithelial cells [27]. Recent findings confirm that the ADAM17-NRG-1HER2 pathway contributes in the pathophysiology of ALI [44]. In addition to these findings, the present study shows that the functional effects of the inflammasome on cell permeability are an IL-1 $\beta$-dependent process. IL-1 $\beta$ RA decreases inflammasome-mediated induction of permeability, showing that additional factors other than IL-1 $\beta$ signaling may be involved in epithelial permeability and therefore further studies may be necessary.

ALI is a heterogeneously diffused respiratory disorder that affects approximately 200,000 patients yearly in the United States [1] and no therapies are currently available to cure this disorder. This study demonstrates a way to regulate IL-1 $\beta$-associated disorders such as ALI through the modulation of the inflammasome. Regulating the inflammasome will help control cell permeability and in turn severity of ALI at an early stage by blocking the downstream IL-1 $\beta$-mediated NRG-1 and pHER2 signaling. Hence, in a clinical perspective, targeting the inflammasome the may be a novel therapeutic approach to suppress ALI and protect against other inflammasome-mediated inflammatory diseases.

\section{Acknowledgements}

NK was supported by National Institutes of Health Grant R01 HL105932 and American Heart Association National Scientist Development Grant 09SDG2260957 and the Joy McCann Culverhouse and Mabel and Ellsworth Simmons Endowments to the Division of Allergy and Immunology.

\section{Disclosure Statement}

The authors have no conflict of interest.

\section{References}

1 Rubenfeld GD, Caldwell E, Peabody E, Weaver J, Martin DP, Neff M, Stern EJ, Hudson LD: Incidence and outcomes of acute lung injury. N Engl J Med 2005;353:1685-1693.

2 Dushianthan A, Grocott MP, Postle AD, Cusack R: Acute respiratory distress syndrome and acute lung injury. Postgrad Med J 2011;87:612-622.

-3 Al-Sadi RM, Ma TY: Il-1beta causes an increase in intestinal epithelial tight junction permeability. J Immunol 2007;178:4641-4649.

Ware LB, Matthay MA: The acute respiratory distress syndrome. N Engl J Med 2000;342:1334-1349. Liu W, Ding I, Chen K, Olschowka J, Xu J, Hu D, Morrow GR, Okunieff P: Interleukin 1beta (il1b) signaling is a critical component of radiation-induced skin fibrosis. Radiat Res 2006;165:181-191.

6 Bellehumeur C, Blanchet J, Fontaine JY, Bourcier N, Akoum A: Interleukin 1 regulates its own receptors in human endometrial cells via distinct mechanisms. Hum Reprod 2009;24:2193-2204. 


\section{Cellular Physiology Cell Physiol Biochem 2015;36:2012-2024 \begin{tabular}{ll|l} 
and Biochemistry 10.1159/000430169 & $\begin{array}{l}\text { D 2015 S. Karger AG, Basel } \\
\text { Published onlne: July 17, } 2015\end{array}$ & www.karger.com/cpb \\
\cline { 2 - 3 }
\end{tabular}}

7 Cao WG, Morin M, Metz C, Maheux R, Akoum A: Stimulation of macrophage migration inhibitory factor expression in endometrial stromal cells by interleukin 1, beta involving the nuclear transcription factor nfkappab. Biol Reprod 2005;73:565-570.

8 Gabay C, Lamacchia C, Palmer G: Il-1 pathways in inflammation and human diseases. Nat Rev Rheumatol 2010;6:232-241.

-9 White SR, Fischer BM, Marroquin BA, Stern R: Interleukin-1beta mediates human airway epithelial cell migration via nf-kappab. Am J Physiol Lung Cell Mol Physiol 2008;295:L1018-1027.

10 Martinon F, Gaide O, Petrilli V, Mayor A, Tschopp J: Nalp inflammasomes: A central role in innate immunity. Semin Immunopathol 2007;29:213-229.

11 Yazdi AS, Drexler SK, Tschopp J: The role of the inflammasome in nonmyeloid cells. J Clin Immunol 2010;30:623-627.

12 Faustin B, Lartigue L, Bruey JM, Luciano F, Sergienko E, Bailly-Maitre B, Volkmann N, Hanein D, Rouiller I, Reed JC: Reconstituted nalp1 inflammasome reveals two-step mechanism of caspase-1 activation. Mol Cell 2007;25:713-724.

13 Sutterwala FS, Ogura Y, Flavell RA: The inflammasome in pathogen recognition and inflammation. J Leukoc Biol 2007;82:259-264.

14 Creagh EM, O'Neill LA: Tlrs, nlrs and rlrs: A trinity of pathogen sensors that co-operate in innate immunity. Trends Immunol 2006;27:352-357.

15 Lee MS, Kim YJ: Signaling pathways downstream of pattern-recognition receptors and their cross talk. Annu Rev Biochem 2007;76:447-480.

16 Artlett CM, Sassi-Gaha S, Rieger JL, Boesteanu AC, Feghali-Bostwick CA, Katsikis PD: The inflammasome activating caspase 1 mediates fibrosis and myofibroblast differentiation in systemic sclerosis. Arthritis Rheum 2011;63:3563-3574.

-17 Lamkanfi M, Kanneganti TD, Franchi L, Nunez G: Caspase-1 inflammasomes in infection and inflammation. J Leukoc Biol 2007;82:220-225.

18 Martinon F, Tschopp J: Inflammatory caspases and inflammasomes: Master switches of inflammation. Cell Death Differ 2007;14:10-22.

19 Xia M, Conley SM, Li G, Li PL, Boini KM: Inhibition of hyperhomocysteinemia-induced inflammasome activation and glomerular sclerosis by nlrp3 gene deletion. Cell Physiol Biochem 2014;34:829-841.

20 Murphy N, Cowley TR, Richardson JC, Virley D, Upton N, Walter D, Lynch MA: The neuroprotective effect of a specific $\mathrm{p} 2 \mathrm{x}(7)$ receptor antagonist derives from its ability to inhibit assembly of the nlrp3 inflammasome in glial cells. Brain Pathol 2012;22:295-306.

21 Kolliputi N, Shaik RS, Waxman AB: The inflammasome mediates hyperoxia-induced alveolar cell permeability. J Immunol 2010;184:5819-5826.

22 Li B, Zheng Z, Wei Y, Wang M, Peng J, Kang T, Huang X, Xiao J, Li Y, Li Z: Therapeutic effects of neuregulin-1 in diabetic cardiomyopathy rats. Cardiovasc Diabetol 2011;10:69.

23 Matsukawa R, Hirooka Y, Nishihara M, Ito K, Sunagawa K: Neuregulin-1/erbb signaling in rostral ventrolateral medulla is involved in blood pressure regulation as an antihypertensive system. J Hypertens 2011;29:1735-1742.

-24 Min SS, An J, Lee JH, Seol GH, Im JH, Kim HS, Baik TK, Woo RS: Neuregulin-1 prevents amyloid beta-induced impairment of long-term potentiation in hippocampal slices via erbb4. Neurosci Lett 2011;505:6-9.

-25 Sawyer DB, Caggiano A: Neuregulin-1beta for the treatment of systolic heart failure. J Mol Cell Cardiol 2011;51:501-505.

26 Horiuchi K, Zhou HM, Kelly K, Manova K, Blobel CP: Evaluation of the contributions of adams 9, 12, 15, 17 , and 19 to heart development and ectodomain shedding of neuregulins beta1 and beta2. Dev Biol 2005;283:459-471.

27 Finigan JH, Faress JA, Wilkinson E, Mishra RS, Nethery DE, Wyler D, Shatat M, Ware LB, Matthay MA, Mason R, Silver RF, Kern JA: Neuregulin-1-human epidermal receptor-2 signaling is a central regulator of pulmonary epithelial permeability and acute lung injury. J Biol Chem 2011;286:10660-10670.

-28 Wilson TR, Lee DY, Berry L, Shames DS, Settleman J: Neuregulin-1-mediated autocrine signaling underlies sensitivity to her2 kinase inhibitors in a subset of human cancers. Cancer Cell 2011;20:158-172.

29 Mandrup-Poulsen T, Pickersgill L, Donath MY: Blockade of interleukin 1 in type 1 diabetes mellitus. Nat Rev Endocrinol 2010;6:158-166. 


\section{Cellular Physiology Cell Physiol Biochem 2015;36:2012-2024 \begin{tabular}{l|l|l} 
and Biochemistry & $\begin{array}{l}\text { DOI: 10.1159/000430169 } \\
\text { Publisnea onlne: July 17, } 2015\end{array}$ & $\begin{array}{l}\text { O) 2015 S. Karger AG, Basel } \\
\text { www.karger.com/cpb }\end{array}$ \\
\cline { 2 - 3 }
\end{tabular}}

-30 Wiersinga WJ: Current insights in sepsis: From pathogenesis to new treatment targets. Curr Opin Crit Care 2011;17:480-486.

31 Stankovic Stojanovic K, Delmas Y, Torres PU, Peltier J, Pelle G, Jeru I, Colombat M, Grateau G: Dramatic beneficial effect of interleukin-1 inhibitor treatment in patients with familial mediterranean fever complicated with amyloidosis and renal failure. Nephrol Dial Transplant 2012;27:1898-1901.

-32 Rajanbabu V, Pan CY, Lee SC, Lin WJ, Lin CC, Li CL, Chen JY: Tilapia hepcidin 2-3 peptide modulates lipopolysaccharide-induced cytokines and inhibits tumor necrosis factor-alpha through cyclooxygenase-2 and phosphodiesterase 4d. J Biol Chem 2010;285:30577-30586.

33 Calvo M, Zhu N, Tsantoulas C, Ma Z, Grist J, Loeb JA, Bennett DL: Neuregulin-erbb signaling promotes microglial proliferation and chemotaxis contributing to microgliosis and pain after peripheral nerve injury. J Neurosci 2010;30:5437-5450.

-34 Olman MA, White KE, Ware LB, Simmons WL, Benveniste EN, Zhu S, Pugin J, Matthay MA: Pulmonary edema fluid from patients with early lung injury stimulates fibroblast proliferation through il-1 betainduced il-6 expression. J Immunol 2004;172:2668-2677.

35 Gimbrone MA, Jr., Nagel T, Topper JN: Biomechanical activation: An emerging paradigm in endothelial adhesion biology. J Clin Invest 1997;100:S61-65.

-36 Queen J, Agarwal S, Dolores JS, Stehlik C, Satchell KJ: Mechanisms of inflammasome activation by vibrio cholerae secreted toxins varies with strain biotype. Infect Immun 2015

37 Dos Santos G, Rogel MR, Baker MA, Troken JR, Urich D, Morales-Nebreda L, Sennello JA, Kutuzov MA, Sitikov A, Davis JM, Lam AP, Cheresh P, Kamp D, Shumaker DK, Budinger GR, Ridge KM: Vimentin regulates activation of the nlrp3 inflammasome. Nat Commun 2015;6:6574.

38 Gasse P, Mary C, Guenon I, Noulin N, Charron S, Schnyder-Candrian S, Schnyder B, Akira S, Quesniaux VF, Lagente V, Ryffel B, Couillin I: Il-1r1/myd88 signaling and the inflammasome are essential in pulmonary inflammation and fibrosis in mice. J Clin Invest 2007;117:3786-3799.

-39 Hoshino T, Okamoto M, Sakazaki Y, Kato S, Young HA, Aizawa H: Role of proinflammatory cytokines il-18 and il-1beta in bleomycin-induced lung injury in humans and mice. Am J Respir Cell Mol Biol 2009;41:661670.

40 Mato N, Fujii M, Hakamata Y, Kobayashi E, Sato A, Hayakawa M, Ohto-Ozaki H, Bando M, Ohno S, Tominaga S, Sugiyama Y: Interleukin-1 receptor-related protein st2 suppresses the initial stage of bleomycin-induced lung injury. Eur Respir J 2009;33:1415-1428.

41 Ortiz LA, Dutreil M, Fattman C, Pandey AC, Torres G, Go K, Phinney DG: Interleukin 1 receptor antagonist mediates the antiinflammatory and antifibrotic effect of mesenchymal stem cells during lung injury. Proc Natl Acad Sci U S A 2007;104:11002-11007.

-42 Park WY, Goodman RB, Steinberg KP, Ruzinski JT, Radella F, 2nd, Park DR, Pugin J, Skerrett SJ, Hudson LD, Martin TR: Cytokine balance in the lungs of patients with acute respiratory distress syndrome. Am J Respir Crit Care Med 2001;164:1896-1903.

43 Wen H, Gris D, Lei Y, Jha S, Zhang L, Huang MT, Brickey WJ, Ting JP: Fatty acid-induced nlrp3-asc inflammasome activation interferes with insulin signaling. Nat Immunol 2011;12:408-415.

44 Finigan JH, Mishra R, Vasu VT, Silveira LJ, Nethery DE, Standiford TJ, Burnham EL, Moss M, Kern JA: Bronchoalveolar lavage neuregulin-1 is elevated in acute lung injury and correlates with inflammation. Eur Respir J 2013;41:396-401. 